\title{
A visita domiciliar como prática pedagógica na formação em Odontologia
}

\author{
Renata Marques da Silva*; Ana Carolina Oliveira Peres**; Daniela Lemos Carcereri*** \\ * Especialista em Saúde da Família na modalidade Residência \\ e Mestranda do Programa de Pós-Graduação em Odontologia, \\ área Odontologia em Saúde Coletiva, Universidade Federal \\ de Santa Catarina \\ ** Especialista em Saúde da Família na modalidade Residência \\ e Doutoranda do Programa de Pós-Graduação em \\ Odontologia, área Odontologia em Saúde Coletiva, \\ Universidade Federal de Santa Catarina \\ *** Docente do Departamento de Odontologia e do Programa de \\ Pós-Graduação em Odontologia, área Odontologia em Saúde \\ Coletiva, tutora da Residência Multiprofissional em Saúde da \\ Família, Universidade Federal de Santa Catarina
}

Recebido em 31/08/2017. Aprovado em 23/10/2017.

\section{RESUMO}

As Diretrizes da Política Nacional de Saúde Bucal destacam a visita domiciliar (VD) como uma das principais formas de ampliação do acesso aos serviços e criação de vínculo com a população, caracterizando-a como um desafio para as Equipe de Saúde Bucal. A adequação dos cursos de Odontologia às Diretrizes Curriculares Nacionais (DCN) implica em preparar o egresso para essa abordagem, utilizando a VD como estratégia pedagógica. Esse estudo investigou as contribuições da VD na formação odontológica, por meio de uma revisão integrativa da produção científica nacional, no período entre 2004 a 2017, compondo uma síntese qualitativa da literatura. Foram pesquisadas quatro bases de dados por meio dos descritores ("home care" OR "home visits") AND ("dentistry" OR "oral health"). Nove estudos compuseram o corpo de análise desta revisão. Dos resultados emergiram quatro categorias: 1- Formação do cirurgião-dentista no Sistema Único de Saúde; 2Compreensão ampliada do processo saúde-doença; 3- O trabalho interdisciplinar; 4- Humanização do Cuidado. Como contribuições à formação evidenciou-se que a VD propiciou ao estudante de Odontologia a vivência no território e a interação com usuários e profissionais da equipe de saúde. $\mathrm{O}$ contato do estudante com a VD possibilita o aprendizado do cuidado à saúde do usuário em seu contexto de vida, bem como a vivência do trabalho interdisciplinar, valorizando os diferentes saberes profissionais. O domicílio demonstrou-se como espaço singular para o aprendizado de vínculo, acolhimento e humanização, o que favorece a formação odontológica na perspectiva da clínica ampliada.

Descritores: Visita Domiciliar. Sistema Único de Saúde. Ensino Superior. Odontologia. 


\section{INTRODUÇÃO}

As Diretrizes Curriculares Nacionais para Cursos de Graduação em Odontologia (DCN) destacam que o futuro cirurgião-dentista (CD) precisa compreender a realidade social, cultural e econômica do seu meio para poder transformála1 . Para isso, a formação deve contemplar, desde o início, o Sistema de Saúde vigente no país, o trabalho em equipe, a atenção integral à saúde em cenários amplos de prática que possibilitem interações ativas com a população e atuação em problemas reais ${ }^{2}$.

No contexto do Sistema Único de Saúde (SUS), a Estratégia Saúde da Família (ESF) reorienta o modelo assistencial, a partir da Atenção Primária à Saúde 3 . O território, a população adscrita, o trabalho em equipe e a intersetorialidade constituem eixos fundamentais da ESF sendo a visita domiciliar (VD) uma de suas ações principais, objetivando ampliar o acesso aos serviços e criar vínculos com a população ${ }^{4}$.

A VD, enquanto categoria da atenção domiciliar $^{5}$, é considerada uma tecnologia de interação no cuidado em saúde sendo fundamental no conhecimento das condições de vida das famílias sob a responsabilidade das equipes $^{6}$. Constitui-se em um eixo transversal do SUS integrando a universalidade, a integralidade e a equidade da atenção em saúde ${ }^{7}$.

Enquanto tecnologia do cuidado, se alinha ao conceito da Clínica Ampliada (CA) descrita na Política Nacional de Humanização (PNH), ao redimensionar a atuação clínica para além das abordagens convencionais. À luz da PNH a assistência à saúde é prestada a uma pessoa, um grupo, uma família ou um coletivo com doença ou risco de adoecer ${ }^{8}$.

Compreende-se a CA como uma ferramenta teórica e prática capaz de considerar a singularidade do sujeito e a complexidade do processo saúde/doença, equilibrando danos e benefícios oriundos das práticas de saúde ao buscar o enfrentamento da fragmentação do conhecimento e das ações de saúde na abordagem clínica do adoecimento e sofrimento ${ }^{9}$.

$\mathrm{Na}$ ESF várias ações são realizadas no contexto do domicílio, como cadastramento das famílias, busca ativa, ações de vigilância, educação em saúde e o Programa Melhor em Casa. O cuidado em saúde também é realizado no domicílio para usuários que demandem acompanhamento permanente ou por algum período e apresentem impossibilidade/ dificuldade de locomoção até à Unidade Básica de Saúde ${ }^{8}$.

Desde a publicação do Caderno de Atenção Básica nº 17 do Ministério da Saúde, a VD vem sendo considerada um dos principais desafios na organização da demanda pela equipe de saúde bucal da $\mathrm{ESF}^{10}$.

$\mathrm{A}$ adequação dos cursos da saúde às $\mathrm{DCN}$ implica considerar o ensino do cuidado domiciliar ${ }^{11}$ e vários deles já utilizam a VD como estratégia pedagógica, preparando os egressos para esse novo contexto de produção do cuidado $^{12-14}$. O avanço do ensino odontológico na perspectiva da CA permitirá que as conquistas do SUS tragam benefícios concretos tanto para o estudante e o profissional de saúde, no desempenho de sua função de transformador da realidade social, quanto para a população, na conquista de seus direitos constitucionais ${ }^{15}$.

Diante do exposto, investigou-se a contribuição da VD enquanto prática pedagógica na formação de sujeitos implicados com a produção do cuidado, respondendo a seguinte pergunta de pesquisa: "Quais são as contribuições da VD na formação de cirurgiõesdentistas?".

\section{METODOLOGIA}

Para responder à pergunta de pesquisa 
utilizou-se o método da revisão integrativa de literatura, considerada um instrumento da prática baseada em evidências (PBE) ${ }^{16}$.

A PBE incentiva o profissional a encontrar, de forma criteriosa e conscienciosa, a melhor evidência para aplicar na sua prática. Dessa forma, os resultados permitirão refletir sobre a contribuição da VD enquanto prática pedagógica na formação de CDs implicados com a produção do cuidado ${ }^{16}$.

Esta revisão integrativa da produção científica nacional, seguiu as seguintes etapas ${ }^{17}: 1$ - elaboração da pergunta norteadora, 2 - busca na literatura, 3 - coleta de dados e elaboração de uma tabela no programa Microsoft Excel ${ }^{\circledR}$ com os dados retirados dos artigos científicos, 4 - análise crítica dos artigos incluídos, 5 - discussão dos resultados e 6 - apresentação da revisão integrativa compondo uma síntese qualitativa da literatura.

A busca na literatura foi realizada nas bases de dados PubMed (Public Medical Literature Analysis Online), LILACS (Literatura Latinoamericana e do Caribe em Ciências da Saúde), SciELO (Scientific Electronic Library Online) e também no Google Acadêmico. Aplicaram-se os seguintes critérios de inclusão: estudos focados na VD e no ensino em Odontologia, originais, publicados entre os anos de 2004 e agosto de 2017, disponíveis online na forma completa. Definiu-se o ano de 2004 como recorte temporal, pela publicação das Diretrizes da Política Nacional de Saúde Bucal (PNSB), cujos pressupostos regem a reorientação do modelo de atenção em saúde bucal no Brasil ${ }^{4}$.

A coleta de dados ocorreu entre maio e agosto de 2017, de forma concomitante nas quatro bases, realizada simultaneamente por dois revisores. A chave de busca utilizada faz parte de um macroprojeto, cujos descritores ou palavraschave pertencem ao Medical Subject Headings (MeSH) ou são seus análogos disponibilizados no DeCS (Descritores em Ciências da Saúde) sendo eles: ("home care" OR "home visits") AND ("dentistry" OR "oral health"), em inglês e/ou português de acordo com a base de dados. Os operadores booleanos " $A N D$ " e "OR" foram utilizados para as combinações.

Ao final nove artigos foram selecionados e a análise crítica foi realizada por dois revisores. Os dados foram analisados à luz da técnica de análise temática $^{18}$ que consistiu em leitura flutuante do conteúdo, codificação, categorização e articulação com os seguintes referenciais teóricos: $\mathrm{PNH}$, com recorte sobre a $\mathrm{CA}$, a PNSB, com foco na reorientação do processo de trabalho do $\mathrm{CD}$ e as DCN com ênfase na premissa da formação em Odontologia no SUS.

\section{RESULTADOS}

Foram encontrados nas 4 bases de dados 1058 estudos. A partir da leitura dos títulos, 1026 foram excluídos por não apresentarem relação com a temática do estudo e 6 por duplicação nas bases de dados. Na próxima etapa, a partir da leitura dos resumos, 5 artigos foram excluídos por não trazerem aspectos de ensino na abordagem da VD. Desta forma, 21 artigos foram selecionados para a leitura na íntegra. Nessa fase, foram excluídos os artigos que não apresentassem o contex to da ESF e a VD como estratégia pedagógica na formação em Odontologia, resultando em nove artigos. As etapas da revisão integrativa encontram-se na figura 1 .

Os nove estudos finais foram organizados no programa Microsoft Excel@, de acordo com os seguintes itens: Autor e ano de publicação, título do artigo, natureza da pesquisa, objetivo do estudo, e as principais contribuições da visita domiciliar enquanto prática pedagógica na formação em Odontologia explicitados no quadro 1.

Dos nove estudos selecionados, oito ${ }^{2,11,20-25}$ 
apontaram a VD como ferramenta pedagógica e espaço privilegiado que contribuiu no processo de aprendizagem em Odontologia e um estudo ${ }^{19}$ elencou tanto contribuições quanto os aspectos negativos da VD. Identificou-se a mesma proporção de estudos com abordagem qualitativa $(n=3 ; 33,3 \%)$, quantitativa $(n=3 ; 33,3 \%)$ e relatos de experiência $(n=3 ; 33,3 \%)$. A maioria dos artigos $(n=5,55,5 \%)$ buscou as percepções ou os significados atribuídos pelos acadêmicos de Odontologia sobre as VDs realizadas ao longo de sua formação $0^{2,19,20}$, ou sobre projetos pedagógicos $^{21}$ e disciplinas ${ }^{22}$ que envolvessem ações extramuros no contexto da ESF, dentre elas a VD.
Apenas um estudo ${ }^{11}$ contou com graduandos de outros cursos da saúde além da Odontologia, egressos e docentes. Os relatos de experiência abordaram as modificações induzidas pelo Programa Nacional da Reorientação da Formação Profissional em Saúde (PRO-SAÚDE) ${ }^{23}$ e PETSaúde $^{24,25}$ na formação em que a VD inseriu os acadêmicos na realidade da ESF.

Do processo de análise emergiram 4 categorias sobre as contribuições da VD enquanto prática pedagógica na formação em Odontologia: 1 - A formação do CD no SUS; 2 A compreensão ampliada do processo saúdedoença; 3 - O trabalho interdisciplinar e 4 - A humanização do cuidado.

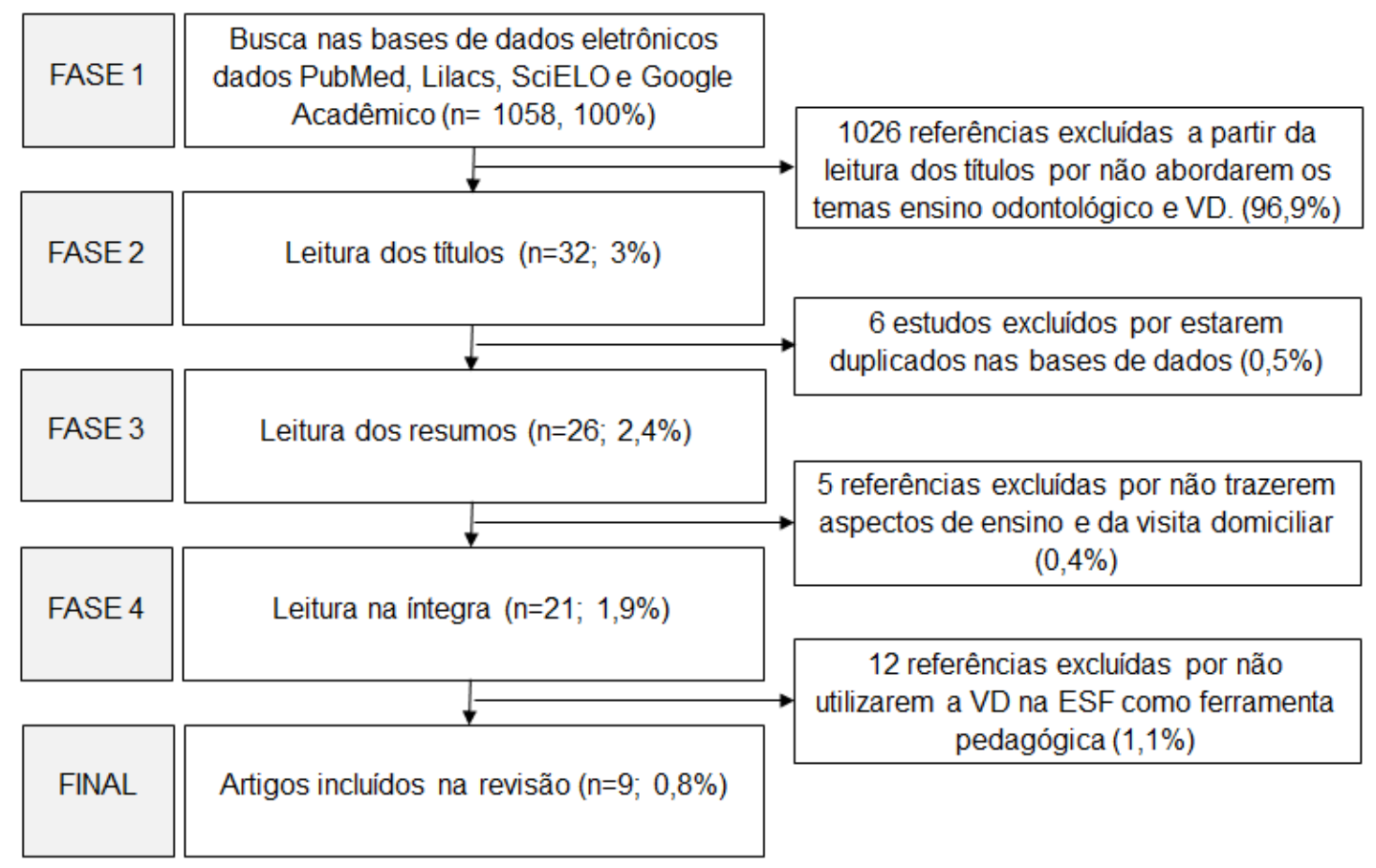

Figura 1. Busca, seleção, inclusão e exclusão dos estudos sobre a contribuição da VD enquanto prática pedagógica na formação de CDs. VD: Visita Domiciliar. ESF: Estratégia Saúde da Família. 
Quadro 1. Resultados da revisão integrativa apresentando o título do estudo, referência e ano de publicação, natureza, objetivos e principais contribuições da visita domiciliar à formação em Odontologia.

\begin{tabular}{|c|c|c|c|c|}
\hline Referência/ano & Título & Natureza & Objetivo & $\begin{array}{c}\text { Principais contribuições da VD à formação } \\
\text { em Odontologia }\end{array}$ \\
\hline Gontijo et al., 2009 & $\begin{array}{l}\text { A saúde bucal coletiva na visão } \\
\text { do estudante de Odontologia - } \\
\text { análise de uma experiência }\end{array}$ & Qualitativa & $\begin{array}{l}\text { Caracterizar o Projeto Saúde } \\
\text { Bucal Coletiva - Saúde e } \\
\text { Cidadania: potencialidades e } \\
\text { fragilidades em relação ao perfil } \\
\text { social do estudante de } \\
\text { odontologia e suas expectativas. }\end{array}$ & $\begin{array}{l}\text { Ação estratégica pedagógica. Primeiro contato } \\
\text { com o território e com práticas de saúde bucal } \\
\text { coletiva. Evidenciou limitações como: horários } \\
\text { desencontrados entre estudantes e famílias a } \\
\text { serem visitadas, repetição e pouca variedade de } \\
\text { ações realizadas no domicílio. }\end{array}$ \\
\hline Morita et al., 2010 & $\begin{array}{l}\text { Visita domiciliar: oportunidade } \\
\text { de aprendizagem na graduação } \\
\text { em Odontologia }\end{array}$ & Qualitativa & $\begin{array}{l}\text { Identificar as percepções de } \\
\text { acadêmicos de Odontologia } \\
\text { sobre visitas domiciliares } \\
\text { realizadas a usuários por eles } \\
\text { atendidos na universidade. }\end{array}$ & $\begin{array}{l}\text { Para os acadêmicos: 1- Foi efetiva no processo } \\
\text { ensino-aprendizagem, revelou a realidade } \\
\text { socioeconômica, cultural e sanitária da } \\
\text { população, oportunizou conhecer os locais onde } \\
\text { acontecem as ações de saúde; } 2 \text {-Ampliou o } \\
\text { conhecimento sobre o processo saúde-doença } \\
\text { pela interação com outros atores; 3- } \\
\text { Humanização da atenção na prática, } \\
\text { fundamental na formação profissional, } \\
\text { cidadania, compromisso social. }\end{array}$ \\
\hline Silva et al., 2011 & $\begin{array}{l}\text { Pró-Saúde Odontologia/ } \\
\text { UNISC: experiências e } \\
\text { contribuições na formação } \\
\text { profissional }\end{array}$ & Quantitativa & $\begin{array}{l}\text { Verificar o impacto do Programa } \\
\text { Nacional de Reorientação da } \\
\text { Formação Profissional em Saúde } \\
\text { nos acadêmicos do curso de } \\
\text { Odontologia da Universidade de } \\
\text { Santa Cruz do Sul. }\end{array}$ & $\begin{array}{l}\text { Possibilitaram conhecer a realidade das famílias } \\
\text { atendidas, conseguindo desta forma ampliar a } \\
\text { visão geral e desenvolver as ações da melhor } \\
\text { maneira possível. }\end{array}$ \\
\hline Palmier et al., 2012 & $\begin{array}{l}\text { Inserção do aluno de } \\
\text { Odontologia no SUS: } \\
\text { Contribuições do Pró-Saúde }\end{array}$ & Relato de experiência & $\begin{array}{l}\text { Relatar a experiência de inserção } \\
\text { dos estudantes no SUS por meio } \\
\text { da disciplina Ciências Sociais } \\
\text { Aplicadas à Saúde, da FO- } \\
\text { UFMG }\end{array}$ & $\begin{array}{l}\text { Evidenciaram os problemas e demandas da } \\
\text { população e seus enfrentamentos diante da } \\
\text { capacidade de resposta do SUS e o } \\
\text { desconhecimento dos estudantes sobre o que é } \\
\text { uma VD. Introdução do conceito de } \\
\text { determinação social da saúde. Aprendizagem } \\
\text { voltada para a realidade e a prática do SUS de } \\
\text { acordo com as DCN. }\end{array}$ \\
\hline
\end{tabular}




\begin{tabular}{|c|c|c|c|c|}
\hline Deneci et al., 2014 & $\begin{array}{l}\text { O significado da participação } \\
\text { em visitas domiciliares pelo } \\
\text { acadêmico de Odontologia }\end{array}$ & Quantitativa & $\begin{array}{l}\text { Analisar a percepção do } \\
\text { estudante de Odontologia quanto } \\
\text { à necessidade da inclusão das } \\
\text { visitas domiciliares }\end{array}$ & $\begin{array}{l}\text { Segundo os estudantes as VD foram entendidas } \\
\text { como importante ferramenta no ensino do } \\
\text { cuidado em saúde, tornando-o contextualizado e } \\
\text { humanizado; a consideraram uma ferramenta } \\
\text { que ajuda na resolução dos problemas e } \\
\text { associaram a realidade de vida das pessoas com } \\
\text { o seu contexto bucal. É uma atividade } \\
\text { humanística e técnica que não pode ser } \\
\text { dispensada pelos acadêmicos. O Pró-Saúde foi } \\
\text { um indutor de mudanças. }\end{array}$ \\
\hline Souza et al., 2014 & $\begin{array}{l}\text { O PET-Saúde na formação } \\
\text { acadêmica em Odontologia: } \\
\text { contribuições e perspectivas. }\end{array}$ & Relato de experiência & $\begin{array}{l}\text { Relatar as experiências dos } \\
\text { acadêmicos de Odontologia no } \\
\text { desenvolvimento de ações de } \\
\text { ensino, pesquisa e extensão } \\
\text { realizadas pelo PET-Saúde, e } \\
\text { suas perspectivas na formação } \\
\text { profissional. }\end{array}$ & $\begin{array}{l}\text { VD enquanto meio de capacitação para } \\
\text { preceptores do PET-Saúde com foco na } \\
\text { territorialização e uso do genograma. Essa } \\
\text { abordagem favoreceu a inserção no território, } \\
\text { destacou a importância de atividades de ensino, } \\
\text { pesquisa e extensão como essenciais ao } \\
\text { aprendizado dos acadêmicos focalizando a } \\
\text { atuação clínica e comunitária. }\end{array}$ \\
\hline Noro e Torquato, 2015 & $\begin{array}{l}\text { Visita domiciliar: estratégia de } \\
\text { aproximação à realidade social? }\end{array}$ & Quantitativa & $\begin{array}{l}\text { Conhecer a percepção dos alunos } \\
\text { do curso de Odontologia da } \\
\text { Universidade de Fortaleza sobre } \\
\text { o aprendizado na área da saúde } \\
\text { bucal coletiva, vivenciado } \\
\text { durante as atividades práticas e a } \\
\text { percepção sobre o SUS. }\end{array}$ & $\begin{array}{l}\text { Positivos: VD enquanto elo com a realidade; } \\
\text { humanização; benefício à comunidade através } \\
\text { das ações de educação em saúde; possibilidade } \\
\text { de acesso ao atendimento clínico no curso de } \\
\text { Odontologia da Unifor; melhores condições de } \\
\text { saúde bucal e a conscientização dos moradores. } \\
\text { Negativos: VD não possui qualquer aspecto } \\
\text { importante para formação; não traz benefícios } \\
\text { para a comunidade. Desafios: estabelecer } \\
\text { vínculo, mudar a perspectiva do atendimento } \\
\text { clínico domiciliar e a visão odontocêntrica. VD } \\
\text { que extrapolem a coleta de dados cadastrais e } \\
\text { aprofundem o conhecimento e prática } \\
\text { humanizada do cuidado. }\end{array}$ \\
\hline
\end{tabular}




\section{DISCUSSÃO}

\section{A formação do CD no SUS}

As DCNs, o PRÓ-SAÚDE e o PET-Saúde foram destacadas como responsáveis pela maior aproximação entre as Instituições de Ensino Superior (IES) com os serviços, ampliando os cenários de prática ${ }^{2,11,19,20,22-25}$. Nesse contexto, a VD foi considerada uma estratégia pedagógica que favorece o desenvolvimento simultâneo ${ }^{22} \mathrm{de}$ diferentes habilidades e competências, como decisão, liderança, educação permanente, responsabilização, comunicação ${ }^{24}$, humanização no atendimento, vínculo e acolhimento ${ }^{2}$.

No que se refere à formação para o SUS, a CA traz o desafio de inovar nas práticas de produção de saúde. Visa integrar a complexidade e variabilidade dos fatores e dos recursos envolvidos na abordagem de problemas de saúde, sejam eles individuais ou coletivos ${ }^{26}$.

Nessa perspectiva a VD mostra-se como potente prática capaz de inserir o estudante de Odontologia no território, aproximando-o dos usuários e dos profissionais da equipe de saúde. A partir deste contato com a realidade in loco $^{2,19,20,23,24}$, o acadêmico vivencia os desafios do cotidiano dos usuários e dos serviços de saúde, e tem a oportunidade de refletir, com base na experiência concreta, sobre as contradições entre a clínica tradicional regida pelo modelo biomédico e a CA.

Durante a VD o cuidado à saúde é dirigido a uma pessoa, um grupo, uma família com doença ou risco de adoecer, e não a uma boca. A visão humanística propiciada pela VD oportuniza o deslocamento da atuação do futuro profissional da Odontologia para além do preenchimento de protocolos de atendimento aos usuários que, via de regra, restringe sentimentos, ignoram valores e saberes ${ }^{27}$. Esse processo de compreensão da realidade social, cultural e econômica na qual está inserido, preconizado pelas $\mathrm{DCNs}^{1}$, é o gatilho para que novas práticas de cuidado em saúde bucal possam se desenvolver afim de se configurar uma CA no ensino da Odontologia para a formação de um profissional críticoreflexivo e capaz de transformar a realidade ${ }^{27}$.

O espaço do domicílio é essencialmente um lugar do encontro, usuário-aluno-professorprofissional, e as relações que se estabelecem no ato de cuidar entre esses sujeitos produzem sentidos e subjetivações para cada um deles. Esse sentido produzido no ato é um dos potenciais da VD na formação profissional e que a diferencia das clínicas universitárias e de aulas centradas no saber docente, agregando outras possibilidades de problematizações durante a prática, para além do saber científico, que evidenciem os diferentes modos de produção do viver e das singularidades ${ }^{28,29}$.

A compreensão ampliada do processo saúdedoença

A VD enquanto espaço pedagógico mostrou contribuir na compreensão ampliada do processo saúde-doença, pois desvela barreiras de acesso no território, aspectos estruturais do domicílio, as condições de vida das pessoas, seus valores, comportamentos, organização social e dinâmica familiar conduzindo o estudante a compreender que a saúde bucal não é restrita aos aspectos biológicos, mas socialmente produzida $^{2,11,19-24}$.

Este contato com o cotidiano durante a formação é fundamental para que os estudantes percebam que não são os usuários que individualmente determinam sua condição de saúde bucal, mas a soma desses vários fatores que promovem saúde ou geram doenças. A partir dessa compreensão ampliada do processo saúdedoença pelos estudantes, espera-se que sejam capazes de compreender que "as maneiras de viver podem sinalizar as maneiras de cuidar" 30 superando uma prática que desconsidere a 
determinação de processos sociais complexos, fundamentada puramente nos aspectos biológicos e individuais ${ }^{31}$.

$\mathrm{Na}$ medida em que a realidade complexa vivenciada pelos usuários, muitas vezes estranha aos estudantes ${ }^{21}$, passa a mediar o processo de aprendizagem $^{23}$, surge o tensionamento e a necessidade de ampliar o cuidado à saúde para além da boca, considerando o indivíduo como um todo. O contexto domiciliar humaniza a relação e pode contribuir para que a plano terapêutico não seja meramente uma prescrição de hábitos saudáveis com enfoque na doença, mas usuário-centrada ${ }^{2,11,19,20,21,24}$.

A visão de que o trabalho da Odontologia seria restrito à boca foi construída enquanto prática social $^{30}$. Cabe destacar que um dos artigos selecionados ${ }^{19}$ trouxe essa visão odontocêntrica apresentada por alguns estudantes, que não perceberam na VD qualquer benefício para sua formação, sendo que o maior benefício para a comunidade seria o acesso ao tratamento odontológico nas clínicas da faculdade. Esses autores ${ }^{19}$ discutiram a necessidade da VD se desenvolver na lógica da humanização do atendimento propiciando o vínculo do estudante com a família e não apenas a coleta pontual de informações acerca do domicílio.

Para que ocorra uma genuína reorganização de modelo de atenção à saúde bucal, é fundamental que a busca dos dentes, da cárie, da lesão não seja o único enfoque da prática $^{30}$. Além disso, a responsabilização por parte dos estudantes de Odontologia com a realidade familiar vivenciada na VD, pode favorecer ações solidárias e criativas na superação das limitações impostas pelas condições socioeconômicas, pelas barreiras geográficas do território ou pela infraestrutura disponível nos serviços de saúde ${ }^{2,21-24,32}$.

Urge a necessidade de exercitar o potencial criativo na formação em saúde, não colocando a doença como fator principal do cuidar, mas ampliando a capacidade de invadir novos territórios existenciais, saindo em busca de experiências de formação que se projetem sobre territórios onde haja o contato com outras culturas, outros modos de viver a vida, em espaços pedagógicos capazes de romper com uma única verdade ${ }^{28}$.

\section{O trabalho interdisciplinar}

A VD durante as diferentes etapas da formação do cirurgião-dentista demonstrou produzir uma aprendizagem que tem a realidade e a prática do SUS como objetos de ensino, compreendendo a importância de integrar os diferentes saberes na busca por intervenções adequadas às distintas demandas dos usuários, propiciando uma relação cooperativa entre as categorias profissionais.

Pensar e fazer CA em saúde bucal é considerar a diversidade de patologias da clínica, que não se restringem ao elemento dental, desafiando os profissionais a verem o paciente como um todo, realizarem consultas junto com outros profissionais, potencializarem o trabalho do pessoal auxiliar, referenciarem e contrarreferenciarem o usuário dentro da rede de atenção à saúde na construção do cuidado integral $^{33}$.

Em um dos estudos selecionados ${ }^{24}$, ficou evidente que a vivência pelo estudante de Odontologia do trabalho interprofissional e interdisciplinar e a aproximação horizontal com o usuário, fortaleceu a integração ensino-serviçocomunidade tornando possível o planejamento terapêutico compartilhado entre os diferentes atores. Nessa direção, outro estudo ${ }^{2}$ corrobora com esse achado e acrescenta que o contexto domiciliar contribuiu para uma abordagem integral direcionada à autonomia e emancipação do usuário.

Assim, o estudante pode ser estimulado a 
conectar diferentes conteúdos e aproximar os saberes científicos da prática profissional em saúde bucal coletiva, incorporando ao processo formativo ${ }^{22}$ os saberes dos profissionais de saúde e dos usuários, ampliando os 'meios' de aprender a fazer a prática clínica, tornando a formação mais humanista e reflexiva ${ }^{2,11,20,22-24}$. Isso está de acordo com a complexidade do trabalho em saúde que é por natureza interdisciplinar e interprofissional e encontra na proposta da CA a articulação entre os diferentes enfoques e disciplinas, com vistas a superar a fragmentação do processo de trabalho ${ }^{9}$.

Todas essas vivências durante a VD podem, ainda, provocar reflexões críticas por parte do estudante frente à imagem do SUS precarizado e ineficaz incutida no imaginário popular, e demonstrar que, embora existam as limitações do sistema, da mesma forma existem profissionais comprometidos com a abordagem comunitária e que conseguem criar alternativas e soluções para os problemas de saúde enfrentados pela população ${ }^{2}$.

\section{A humanização do cuidado}

O domicílio demonstrou-se como espaço singular para o aprendizado de vínculo $\mathrm{e}$ acolhimento, visto que são temáticas que podem ser melhor compreendidas fora do contexto institucionalizado das salas de aula, clínicas e laboratórios das escolas de Odontologia. A produção do cuidado humanizado requer uma relação afetiva e de confiança entre o estudante, os profissionais de saúde, o usuário e o professor, para que se desenvolva autonomia, comunicação e inovações assistenciais para além do procedimental e técnico, instigando o estudante a desenvolver uma atuação adequada ao contexto domiciliar essencialmente dinâmico ${ }^{2,11,19,20}$.

Para isso é necessário que o estudante de Odontologia tenha uma postura proativa, mas também é importante refletir sobre os sentimentos complexos envolvidos com demandas observadas na VD, que podem gerar ansiedade, frustração, tristeza. A capacidade de lidar com o inesperado ao sair do lugar habitual do consultório odontológico requer que o professor esteja atento no processo de aprendizado de cada estudante, humanizando a formação também nesse sentido ${ }^{19}$.

O vínculo e o comprometimento na relação entre os atores e sujeitos é a chave para promover novos arranjos tecnológicos e adequar as práticas de saúde bucal e com as diretrizes da PNSB e da ESF. Por isso, é necessário que a formação dos profissionais esteja sensível ao cotidiano dos usuários para que o cuidado em saúde e o projeto terapêutico seja mais próximo da necessidade do sujeito e respeite sua subjetividade ${ }^{30}$.

Para que efetivamente as diretrizes da PNSB transformem a prática em saúde bucal e promovam novos arranjos tecnológicos no processo de trabalho, torna-se clara a necessidade de melhorar a formação dos profissionais na direção de práticas consoantes aos fundamentos da ESF e sensíveis ao cotidiano daqueles para os quais se planeja um projeto terapêutico.

Todavia, é necessário que não se confunda vínculo com dependência do usuário à presença do profissional de saúde. As práticas em saúde bucal baseadas na CA precisam ser emancipatórias, orientadas para promover autonomia do usuário sobre os modos de viver a vida ${ }^{9}$.

\section{CONSIDERAÇÕES FINAIS}

Evidenciou-se que a VD contribuiu nesse novo agir pedagógico como um cenário propício para que o estudante de Odontologia se aproxime dos usuários, do território e dos demais profissionais da equipe de saúde, indo ao encontro com o preconizado pelas DCN.

Desenvolveu-se a compreensão do processo saúde-doença por meio do contato do 
estudante com a realidade social deslocando o foco da abordagem para o usuário e seu contexto de vida, bem como a vivência do trabalho interdisciplinar e em equipe, valorizando os diferentes saberes profissionais no âmbito do domicílio e do território.

Além disso, a VD provocou reflexões críticas nos estudantes frente à imagem do SUS incutida no imaginário popular. $\mathrm{O}$ domicílio demonstrou-se como espaço singular para o aprendizado de vínculo, acolhimento e humanização, o que favorece a formação odontológica na perspectiva da CA e em consonância com o perfil estabelecido pelas DCNs.

\section{ABSTRACT \\ The home visit as a pedagogical practice in Dentistry training}

The National Oral Health Policy Guidelines emphasize home visits (HV) as one of the main ways to increase access to services and engender bonds with population, considering the $\mathrm{HV}$ as a challenge for the Oral Health Team. The appropriateness of the Dentistry Courses (2002) to the National Curriculum Guidelines (DCN) involves preparing the former student for this approach, using the $\mathrm{HV}$ as a pedagogical strategy. This study investigated the contributions of the $\mathrm{HV}$ in dental education, through an integrative review of the national scientific production, between 2004 and 2017, composing a qualitative synthesis of the literature. Four databases were searched through these keywords ("home care" OR "home visits") AND ("dentistry" OR "oral health"). Nine articles composed the analysis of this review. From the results emerged four categories: 1 Dental Education on Unified Health System (SUS); 2 - Enlargement of the health-disease process understanding; 3 - Interdisciplinary work; 4 - Care Humanization. As contributions to dental education, it was evidenced that the HV allowed the Dentistry student to experience the territory and interact with SUS users and professionals of the health team. The student's contact with the HV makes it possible to learn the health care of the user in their life context, as well as the experience of the interdisciplinary work, valuing the different professional knowledge. The household was shown as a unique space for learning of bond relationship, reception and humanization, which favors dental education from the perspective of the expanded clinic.

Descriptors: Home Visits. Unified Health System. Education, Higher. Dentistry.

\section{REFERÊNCIAS}

1. Brasil. Ministério da Educação. Diretrizes Curriculares Nacionais do Cursos de Graduação em Farmácia e Odontologia. [Acesso em 20 jul. 2017]. Disponível em: http://portal.mec.gov.br/cne/arquivos/pdf/C ES1300.pdf

2. Morita MC, Codato LAB, Higasi MS, Kasai MLHI. Visita domiciliar: oportunidade de aprendizagem na graduação em Odontologia. Rev Odontol UNESP. 2010;39(2):75-9.

3. Alves VS. Um modelo de educação em saúde para o Programa Saúde da Família: pela integralidade da atenção e reorientação do modelo assistencial. Interface Comun Saúde Educ. 2005;9(16):39-52.

4. Brasil. Ministério da Saúde. Brasil Sorridente. Portal do Departamento de Atenção Básica. [Acesso em 20 jul. 2017.] Disponível em: http://189.28.128.100/dab/ docs/publicacoes/geral/diretrizes_da_politic a_nacional_de_saude_bucal.pdf.

5. Cunha CLF, Gama MEA. A visita domiciliar no âmbito da atenção primária em saúde. In: Malagutti W. (Org.). Assistência Domiciliar - Atualidades da Assistência de Enfermagem. Rio de Janeiro: Rubio; 2012, p.37-48.

6. Takahashi RF, Oliveira, MAC. A visita domiciliária no contex to da saúde da família. In: Brasil. Ministério da Saúde. Programa de 
Saúde da Família: manual de enfermagem. São Paulo: Ministério da Saúde; 2001, p. 4346.

7. Lopes WO, Saupe R, Massaroli A. Visita Domiciliar: tecnologia para o cuidado, o ensino e a pesquisa. Ciênc Cuid Saúde. 2008;7(2):241-7.

8. Brasil. Ministério da Saúde. Secretaria de Atenção à Saúde. Departamento de Atenção Básica. Caderno de atenção domiciliar. Brasília: Ministério da Saúde, 2012. [Acesso em 10 jun. 2017]. Disponível em: http://189.28.128.100/dab/docs/publicacoes /geral/cad_vol1.pdf.

9. Brasil. Ministério da Saúde. Política Nacional de Humanização da Atenção e Gestão do SUS. Clínica ampliada e compartilhada. Brasília: Ministério da Saúde, 2009. [Acesso em 21 jul. 2017]. Disponível em: http://bvsms.saude.gov.br/ bvs/publicacoes/clinica_ampliada_comparti lhada.pdf

10. Brasil. Ministério da Saúde. Saúde Bucal. Brasília: Ministério da Saúde, 2008. [Acesso em 21 jul. 2017]. Disponível em: http://bvsms.saude.gov.br/bvs/publicacoes/s aude bucal.pdf.

11. Hermann AP, Lacerda MR, Maftum MA, Bernardino E, Mello ALSF. O processo de ensinar e aprender o cuidado domiciliar nos cursos de graduação em saúde. Ciênc Saúde Coletiva. 2017;22(7):2383-92.

12. Romanholi RMZ, Cyrino EG. A visita domiciliar na formação de médicos: da concepção ao desafio do fazer. Interface Comun Saúde Educ. 2012;16(42):693-705.

13. Silva FAG. A visita domiciliar como estratégia pedagógica e seus sentidos para estudantes dos cursos de enfermagem, medicina e odontologia em um centro universitário do estado do Rio de Janeiro [dissertação]. Rio de Janeiro: Escola
Nacional de Saúde Pública Sérgio Arouca; 2012.

14. Borges FR, Avelino CCV, Costa LCS, Lourenço DS, Sá MD, Goyatá SLT. Ensino sobre visita domiciliar a estudantes universitários. Rev Rene. 2017;18(1):12938.

15. Noro LRA, Torquato SM. Percepção sobre o aprendizado de saúde coletiva e o SUS entre alunos concludentes de curso de Odontologia. Trab Educ Saúde. 2010;8(3):439-47.

16. Coscrato G, Pina JC, Mello DF. Utilização de atividades lúdicas na educação em saúde: uma revisão integrativa da literatura. Acta Paul Enferm. 2010;23(2):257-63.

17. Souza MT, Silva MD, Carvalho R. Revisão integrativa: o que é e como fazer. Einstein. 2010;8(1):102-6.

18. Minayo MCS. O desafio do conhecimento: pesquisa qualitativa em saúde. 12ed. São Paulo: Hucitec; 2010. 406p.

19. Noro LRA, Torquato SM. Visita domiciliar: estratégia de aproximação à realidade social? Trab Educ Saúde. 2015;13(1):14558.

20. Deneci V, Medeiros B, Silva D, Vidal K, Chevitarese L. O significado da participação em visitas domiciliares pelo acadêmico de Odontologia. Rev ABENO. 2014; 14(1): 6672.

21. Gontijo LPT, Almeida MCP, Gomide LRS, Barra RP. A saúde bucal coletiva na visão do estudante de Odontologia - análise de uma experiência. Ciênc Saúde Coletiva. 2009;14(4):1277-85.

22. Silva MC, Marques BB, Reis MS, Moraes RB. Pró-Saúde - Odontologia/UNISC: experiências e contribuições na formação profissional. Rev ABENO. 2011;11(1):4750.

23. Palmier AC, Amaral JHL, Werneck MAF, 
Senna MIB, Lucas SD. Inserção do aluno de Odontologia no SUS: contribuições do PróSaúde. Rev Bras Educ Méd. 2012;36(1, Supl. 2):152-7.

24. Mecca LE, Jitumori RT, Warkentin PF, Baldani MH, Borges PKO. Visitas domiciliares: vivenciando o emprego das diretrizes curriculares na Odontologia, da teoria à pratica. Rev ABENO. 2013;13(2): 62-8.

25. Souza GCLL, Lopes MRL, Rodrigues CAQ, Moreira KS, Oliveira MP, Morais AJD, et al. O PET- Saúde na formação acadêmica em Odontologia: contribuições e perspectivas. Rev ABENO. 2014;14(1):73-80.

26. Campos GWS, Domitti AC. Apoio matricial e equipe de referência: uma metodologia para gestão do trabalho interdisciplinar em saúde. Cad Saúde Públ. 2007;23(2):399407.

27. Hayacibara MF, Lolli LF, Terada RSS, Hidalgo MM, Bispo CGC, Terada HH, et al. Experiência de Clínica Ampliada em Odontologia na Universidade Estadual de Maringá. Rev Bras Educ Méd. 2012; 36(1):178-83.

28. Abrahão AL, Merhy EE. Formação em saúde e micropolítica: sobre conceitosferramentas na prática de ensinar. Interface Comun Saúde Educ. 2014; 18(49):313-24.
29. Franco TB, Merhy EE. Atenção domiciliar na saúde suplementar: dispositivo da reestruturação produtiva. Ciênc Saúde Coletiva. 2008;13(5):1511-20.

30. Narvai PC. Saúde bucal coletiva: caminhos da odontologia sanitária à bucalidade. Rev Saúde Pública. 2006;40:141-147.

31. Pires FS, Botazzo C. Organização tecnológica do trabalho em saúde bucal no SUS: uma arqueologia da política nacional de saúde bucal. Saúde Soc. 2015;24(1):273284.

32. Feuerwerker LCM, Merhy EE. A contribuição da atenção domiciliar para a configuração de redes substitutivas de saúde: desinstitucionalização e transformação de práticas. Rev Panam Salud Pública. 2008;24(3):180-8.

33. Martino LVS, Botazzo C. Formação para a clínica ampliada de saúde bucal: uma proposta metodológica (e mudança de olhar). BIS, Bol Inst Saúde. 2007;43:10-14.

Correspondência para:

Renata Marques da Silva

e-mail: odontologiarenata@gmail.com

Rua José João Martendal, 122 - Trindade

88040-420 - Florianópolis/SC 